\title{
Analysing Lesbian, Gay, Bisexual, Transgender and Queer or Questioning (LQBTQ) Cyberbullying Using Unsupervised Associative Approach Text Analytics Technique
}

\author{
FREDERICK F. PATACSIL, JENNIFER M PARRONE, \\ CHRISTINE LOURRINE TABLATIN, MICHAEL ACOSTA \\ College of Computing \\ Pangasinan State University \\ Urdaneta City, Pangasinan \\ PHILIPPINES
}

\begin{abstract}
Cyberbullying has become one of the major threats in our society today due to the massive damage that it can cause not only in the cyber world and the internet-based business but also in the lives of many people. The sole purpose of cyberbullying is to hurt and humiliate someone by posting and sending threats online. However, recognition of cyberbullying has proved to be a hard and challenging task for information technologists. The main objective of this study is to analyze and decode the ambiguity of human language used in cyberbullying Lesbian, Gay, Bisexual, Transgender and Queer or Questioning (LGBTQ) victims and detect patterns and trends from the results to produce meaning and knowledge. This study will utilize an unsupervised associative approach text analysis technique that will be used to extract the relevant information from the unstructured text of cyberbullying messages. Furthermore, cyberbullying incidence patterns will be analyzed based on recognizing relationships and meaning between cyberbullying keywords with other words to generate knowledge discovery. "Fuck" and "Shit" account almost half of all cyberbullying words and appear more that $75 \%$ in the dataset as the most frequently used words. Further, the terms "shit"+"hate"+ "fuck" with a positive lift value and "shit"+ "stupid" positive obtained the highest chance of togetherness / chance of utilizing both of these words to cyber bully. The combination of words / word patterns was considered abusive swearing is always considered rude when it is used to intimidate or humiliate someone. The output and results of this study will contribute to formulating future intervention to combat cyberbullying. Furthermore, the results can be utilized as a model in the development of a cyberbullying detection application based on the text relations / associations of words in the comments, replies, blog discussion and discussion groups across the social networks.
\end{abstract}

Key-Words: - Cyberbullying, LGBTQ, Bullying, Cyber, Association Rule, Text Analytics

Received: May 7, 2021. Revised: October 16, 2021. Accepted: November 12, 2021. Published: December 2, 2021.

\section{Introduction}

Cyberbullying has become one of the major threats in our society today due to the massive damage that it can cause not only in the cyber world and the internet-based business but also in the lives of many people. The sole purpose of cyberbullying is to hurt and humiliate someone by posting and sending threats online. However, recognition of cyberbullying has proved to be a hard and challenging task for information technologists. To deeply study and analyse cyberbullying is difficult because of the incorporeal nature of cyberbullying that makes social media a perfect fit for bullies. Some research has revealed data about bullying ranging from $51 \%$ to $58 \%$ of victimization in people with non-normative sexual orientation/identity. Cyber victimization rates are between $10 \%$ and $71 \%$ in LGBTs[1]. Some research has shown that
LGBTQs who have been victims of bullying and cyberbullying at school show depression and anxiety [2]. Research also shows that the relationship between suicidal ideation and bullying was stronger in gays, lesbians, and queers, compared to bisexuals, heterosexuals, and those who were uncertain of their sexual orientation. Hence, there is hardly any research that analyses cyberbullying for uncertain of their sexual orientation. Analyzing the incidence of cyberbullying requires a complex understanding of language and text structures. The complications underlying these activities make automatic detection problematic for static computational approaches. For example, text analytics that uses a keyword or bag of word analysis is inadequate to identify occurrences of textual cyberbullying as an existing bag of words text analysis tools often use an 
incomplete cyberbullying keyword dictionary. Text analysis can be helpful to researchers to deal with these kinds of issues in unstructured information to find meanings or knowledge in this textual information. Text analysis is the automated process of obtaining information from unstructured textual information using an associative approach that focuses on understanding how keyword relates to one another keyword. Collocation (two adjacent words e.g., 'best cake' or 'sales support') method help identify words that commonly co-occur and seek the hidden meaning of the words. Thus, it improves the granularity of the insights by counting programs as one word. This method could be employed to decode the ambiguity of the human language to a certain extent, by looking at how words are used in different contexts, as well as being able to analyse more complex phrases. The important information could be extracted from the unstructured text of cyberbullying messages and can be used to recognize the relationship and meaning between cyberbullying keywords with other words. Thus, this study would help to decode the ambiguity of human language used in the cyberbullying homosexual victims.

The main objective of this study is to analyze and decode the ambiguity of human language used in cyberbullying Lesbian, Gay, Bisexual, Transgender and Queer or Questioning (LGBTQ) victims and detect patterns and trends from the results to produce meaning and knowledge. This study will utilize an unsupervised associative approach text analysis technique that will be used to extract the relevant information from the unstructured text of cyberbullying messages. Furthermore, cyberbullying incidence patterns will be analyzed based on recognizing relationships and meaning between cyberbullying keywords with other words to generate knowledge discovery.

\section{Literature Review}

Cyberbullying also known as cyber victimization, online victimization, and online aggression, is the hostile actions, activities and manners done online which aim to inflict harm and pain to a person or a group of people [3][4]. It is also defined as a deliberate and recurrent pattern of harm inflicting behavior, tormenting, threatening, embarrassing or harassing others through the use of electronic devices like computers and cell phones, and the internet [5][6][7]. Hinduja and Patchin [5] further expounded the definition of cyberbullying by giving the following synonyms for the term: cyber harassment, electronic bullying, internet bullying, e- bullying, digital bullying, SMS bullying, mobile bullying, and text bullying. As Garaigordobil and Larrain [8] put it, cyberbullying is a kind of bullying which uses information and communication technologies and the internet. Thus, cyberbullying is prevalent in internet chat rooms, online blogs, emails, and instant messaging consequently making social media or social networking sites as cyberbullying platforms [9] [10] [6]. For Powell et al. [11], they named cyberbullying digital harassment and defined it as negative online behaviors which include name calling and offensive comments, directed harassment, verbal threats, and abuse. They also termed gender-targeted cyberbullying as sexual, sexuality, and gender-based harassment, which means "harmful and unwanted behavior either of a sexual nature or directed at a person on the basis of their sexuality or gender identity" and this includes cyberstalking, sexual solicitation, and sexting.

\subsection{LGBTQ Cyberbullying}

There is a gender gap in the accessibility and in the effectiveness of education [12] [13] as well as in cyberbullying. When it comes to minorities, is no longer new when it comes to minorities and among the minorities, bullying is more prevalent among homosexuals [3] [8] [5] [14] [15] [16]. In the Research Summary paper of Hinduja and Patchin [2], they discussed the data of different groups, both from the government and NGOs showing that LGBT citizens in the US are "most likely to be targeted" of hate, harassment, bullying, abuse, and violent hate crimes. Powell et al., [11] found that bisexual men and women, and transgenders are more prone to be subjected to digital harassment and abuse; bisexual men were more prone to experience online sexual harassment than their counterparts; gay and bisexual men are more likely to experience gender or sexuality-based harassment. In terms of aggressiveness, Garaigordobil and Larrain [8] found that non-heterosexuals receive more aggressive bullying than their heterosexual counterpart.

\subsection{LGBTQ Cyberbullying Correlates}

In terms of correlates, Abreu and Kenny [3] found that there is a higher correlation between cyberbullying and negative psychological and emotional, behavioral, and academic health outcomes among the LGBTQ+ youth. For the psychological and emotional correlate, they identified the following categories: suicidal ideation and attempt; depression; and lower self-esteem. LGBTQ+ youth who experienced cyberbullying especially if coupled with traditional bullying, are 
most likely to think and attempt committing suicide. Similarly, they have higher levels of depression and very low self-esteem. For the behavioral correlate, they found that cyberbullying coupled with traditional bullying, are more aggressive and more likely to involve in physical fights. Other categories they identified under the behavioral correlates are poor self and body image, isolation from friends and family and fear of going out especially in school. For the academic correlates, they found that LGBTQ+ victims of cyberbullying reported lower performance in school. Similarly, Wiederhold [15], discussed in her paper that non-heterosexual youth tend to be bullied online than their heterosexual counterpart, which, consequently causes serious mental health issues and consequences among them.

The above-mentioned studies corroborate the results of studies which found that victims of homosexual bullying are more likely to suffer harm in their mental health and wellbeing, values, and attitudes, hence they are at risk of committing suicide and inflicting self-harm [16] [17] [18] [11].

\subsection{Patterns in LGBTQ Cyberbullying}

Digitalization is creating and will continue to provide more opportunities to apply automatic digital tools in education, as well as artificial intelligence-based solutions that are scalable and broadly applicable [20]. Web 2.0 social networking tools allow individuals to meet, produce, share, and broadcast information online [21]. Sharing opinions, attitudes, and knowledge are essential [22], but sometimes opinions become offensive to other individuals. The artificial intelligence-based solutions can be applied in determining offensive words that are published in online platforms such as social networking sites.

Patacsil [16] analyzed cyberbullying incidence among Filipina victims and found that in terms of patterns, sex-related intelligence, and demeaning words that describes personality and appearance of the victims were the most prevalent cyberbullying words used. His study yielded the following words as most commonly used to cyberbully Filipino women: (1) "gaga," the most frequently used word, and it is associated with foolishness, idiocy, ignorance and stupidity, (2) the second most frequently used word is "tangina," a clipped version of the Filipino profane expression, "putang ina mo" which means "your mother is a prostitute," next is (3) "hayop;" a word which deameans a person to a mere animal, and then (4) "pakyu" the Filipinized word for the English expression "Fuck you," (5) "panget" which means ugly, (6) "ulol" which, in English is, crazy like, clinically crazy, (7) "pokpok" meaning a prostitute, a very demeaning word for women, (8) "demonyo" which means devil, and lastly (9) "unggoy" which means monkey, a word, which for Filipinos, is associated with very unpleasant appearance and personality. Similarly, Potha and Maragoudakis [6] explored detecting cyberbullying using Time Series Modeling and discovered that cyberbullying patterns used by online sexual predators start with seemingly normal and safe questions progressing to sexually-laden and harassment questions. In the same manner, Dinakar et al. [19] Explored modelling the detection of textual cyberbullying, learned that the most common patterns of blatant bullying in YouTube comments which are easy to model are verbal abuse and profanity. Sarcasm and euphemism were also found, however, they discovered that these two are less easy to model than the first two patterns. In Indonesia, Margono et al. [10] delved on mining Indonesian cyber bullying patterns in social networks, specifically Twitter, in Jakarta and Surabaya. They found the following as the most commonly occurring cyberbullying patterns, "bangsat", "anjing", "iblis", and "setan."

\section{Methodology}

\subsection{Data Collection}

The first process is the collection of cyberbullying data. The study utilized RapidMiner its Web extensions downloaded online specifically the Search Twitter operator. In the gathering process, it took many runs to achieve the desired dataset results. Changing the value of the parameter query or the phrase in the query will search and retrieve different dataset from Twitter. The parameter or phrase - query determined the term that should be searched and limit the number of tweets to return. The following terms (e.g. "Lesbian", "LGBT", "Homosexual", "Bisexual" and other term) and dirty words ("fucking", "bitch" and other words) were utilized as parameter search possible cyberbullying data. The following criteria were set to determine the characteristics of the tweets:

- The average length of a tweet should be 4 words

in a sentence

- Tweet messages that contain cyberbullying topics were only retained

- Only tweet messages that use English only.

The estimated total dataset of bullying tweets that were gathered were more than 100,000.

Adapting machine learning will maintain a competitive result since it gives a new possibilities in conducting studies [21]. 


\subsection{Data Cleaning}

Data cleaning was utilized after data collection. The study removes duplicate tweets that appeared more than once utilizing a spreadsheet tool and the tweets that contain no bullying intention were manually erased from the dataset. Only those tweets that contain bullying intention were kept and saved for the next step. A PHP application was created and utilized to delete unnecessary characters that have no meaning in the cyberbullying pattern recognition process.

\subsection{Data Selection and Annotation.}

The selection and annotation of the cleaned dataset were made by trained three annotators. They were assigned to manually identify whether the tweets contain cyberbullying tweets or not. The basis of these grouping was based on the research conducted by Bogart [20]. His study found out and suggest that one rater can rate pretty well, but three can rate better and there is not much gain after increasing to three. The annotators were oriented and trained to determine by applying the criteria for bullying words and nearby words in the tweets. Only tweets identified as bullying was considered as part of the dataset. After the data selection and annotation, the exact total of bullying tweets gathered were 9141 .

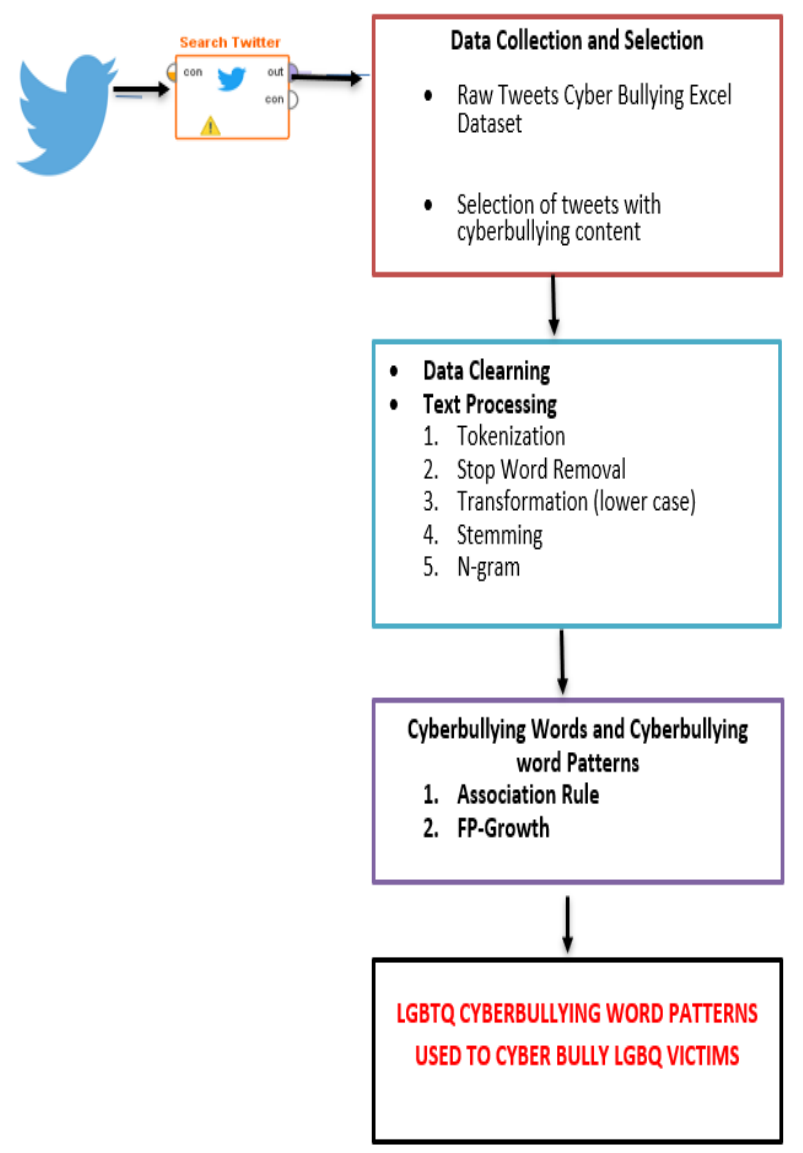

Fig. 1: The Cyberbullying Processing Model

\subsection{Data Preprocessing}

After the data selection and annotation process, the next step employed was the data preprocessing and this task were done using Rapid Miner text processing capability. Data preprocessing includes filtering stop words, stemming, tokenization, case transformation and feature selection or n-gram.

Data Processing process:

- Stop Words Removal used of stopwords (Dictionary English) operator to remove all the words equal to the stopwords from the given tweet's dataset.

- This operator transforms the cases of letters (i.e., lower case or upper case). The study transforms all letters in the data into lower case for the purpose of convenience.

- After case transformation, tokenization was employed. This operator splits the text of a document into a series of tokens. There are several options that can be implied in splitting the text, however the proponent selected the default setting which is the nonletters.

- The last step is to utilize n-gram to learn the meaning of words and its neighbors by connecting a sequence of $\mathrm{n}$ words from a given sequence of tweets.

\subsection{Pattern Recognition Process}

The schema that was utilized to determine the frequency of the words was TF-IDF or Term Frequency - Inverse Document Frequency. This tool was used to measure numeric frequency of terms and to show the importance of cyberbullying words in the collection of tweets dataset. The method was used to determine the dominant cyberbullying words and word patterns in terms of frequency of their appearance/occurrence of words in the tweets. The TF-IDF value increases proportionally to the number of times a word (bullying terms or pronoun) appears in the tweets, but is offset by the frequency of the word in the dataset, which helps to control for the fact that some words are generally more common than others.

\subsection{Association Mining Rule}

This stage presents a way for mining cyberbullying words from a collection of tweets by automatically extracting frequent words in each tweet. 


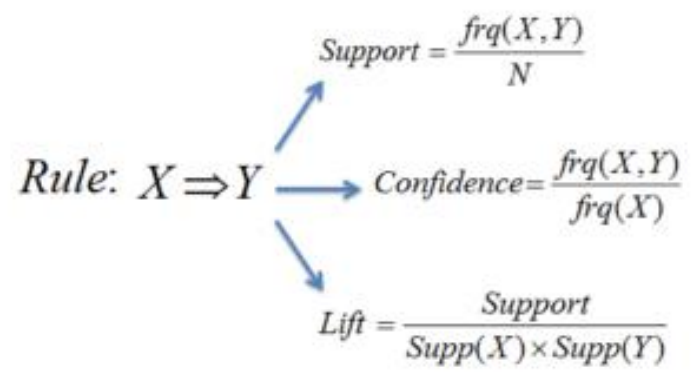

Where:

Support - indicates the frequency a word appears in the dataset.

Confidence - indicates the frequently a rule is found to be true.

Lift $(\boldsymbol{A} \rightarrow \boldsymbol{B})$ - indicates the rise in the probability

of occurrence of word B when word A has already occurred

Support is a set of cyberbullying words or number of cyberbullying tweets in which that set of cyberbullying words occurs in the dataset.

Confidence determines the reliability of the inference made by a rule and is defined as the probability of finding [cyberbullying ${ }^{1}$, cyberbullying ${ }^{\mathrm{n}}$ ] together.

Lift computes the ratio between the rule's confidence and the support of the cyberworld in the rule consequent. If the value of lift rule $>1$ then it has positive correlation. A lift value greater than 1 indicates words appear more often together than expected.

\subsection{FP growth (Frequent Pattern Growth)}

FP growth is creating the frequent datasets without the need for candidate generation. FP growth algorithm is a dataset in the form of a tree called a frequent pattern tree or FP tree. This tree structure will continue to uncover the relationship between two or more items. The datasets are fragmented using one frequent item. This fragmented part is called "pattern fragment". The datasets of these fragmented patterns, then analysed. Thus, with this method, the search for frequent datasets is reduced compared.
Illustration:

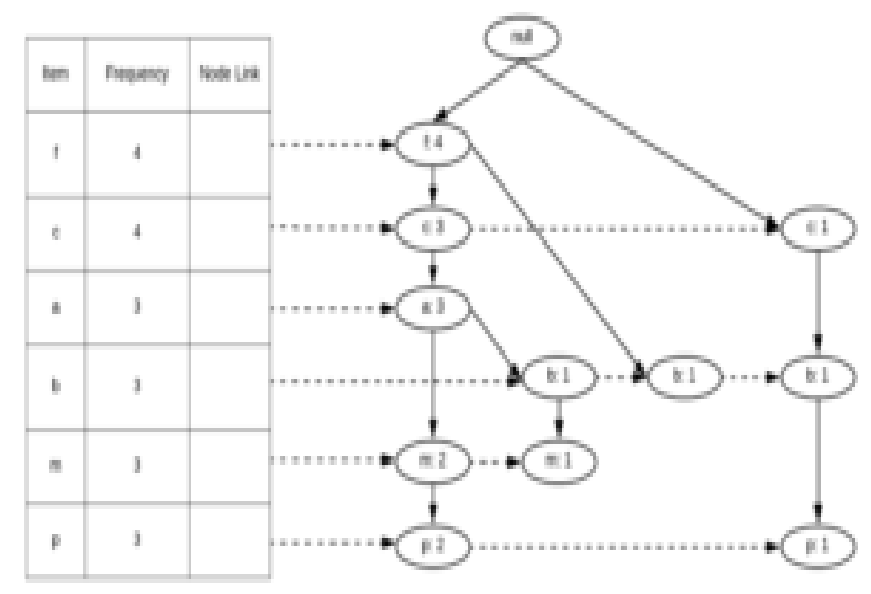

\section{Results and Discussion}

Table 1. Dominant Single Cyberbullying words

\begin{tabular}{|l|l|l|}
\hline Cyberbullying Words & Support & $\begin{array}{l}\text { No. of } \\
\text { time } \\
\text { Appeared } \\
\text { in the } \\
\text { Dataset }\end{array}$ \\
\hline fuck & 0.781 & 78,100 \\
\hline shit & 0.727 & 72,700 \\
\hline holy & 0.102 & 10,200 \\
\hline people & 0.077 & 7,700 \\
\hline hate & 0.047 & 4,700 \\
\hline love & 0.039 & 3,900 \\
\hline Man & 0.035 & 3,500 \\
\hline God & 0.034 & 3,400 \\
\hline Good & 0.032 & 3,200 \\
\hline Gay & 0.032 & 3,200 \\
\hline Ugly & 0.029 & 2,900 \\
\hline Talk & 0.028 & 2,800 \\
\hline Feel & 0.027 & 2,700 \\
\hline Life & 0.027 & 2,700 \\
\hline Stupid & 0.026 & 2,600 \\
\hline bitch & 0.026 & 2,600 \\
\hline piece & 0.026 & 2,600 \\
\hline day & 0.023 & 2,300 \\
\hline & & \\
\hline
\end{tabular}

The prevalent words used to bully in the cyber is "fuck" $(0.78)$ or 78,000 that the word appeared in the dataset, "shit" $(0.727)$ or 72700 times that the word appear dataset, follow after "fuck" and "shit" 
were "holy" (0.102) or 10200, "people" (0.0077) and "hate" $(0.047)$. The word "fuck" or "fucking" obtain the most used word to bully people on the Internet and has several meanings depending on how you use it in a statement. The word fuck in interjection Slang it express anger, disgust, and peremptory rejection. This a word that expresses negatively characterized anything that can be dismissed, disdained, defiled, or destroyed and they considered as a bad word. Another word that was utilized is "shit" a word generally considered to be vulgar and profane in modern English. As a slang term, "shit" has many meanings which include nonsense, foolishness, something of little value or quality, trivial and usually boastful or inaccurate talk or a contemptible person. "Fuck" and "Shit" account almost half of all cyberbullying words and appear more that $75 \%$ in the dataset as the most frequently used words. According to Finn [19] "fuck", "shit" and other vulgar words should not ignore the fact that swearing is an important part of language and recognize that they cannot just hope that students can figure it out on their own, especially when the consequences can be dire, such as losing status, damaging relationships, bullying, and getting into risky situations. Abusive swearing is always considered rude when it is used to intimidate or humiliate someone.

Some of the words have no meaning when utilized as a single word, however, if paired with other words, it gives a more meaningful information which will be presented in the next table.

Table 2. Dominant Double Cyberbullying Words / Word Patterns

\begin{tabular}{|l|l|l|l|}
\hline $\begin{array}{l}\text { Cyberbullyi } \\
\text { ng Word 1 }\end{array}$ & $\begin{array}{l}\text { Cyberbull } \\
\text { ying Word } \\
\text { 2 }\end{array}$ & Support & $\begin{array}{l}\text { No. of time } \\
\text { Appeared } \\
\text { two word } \\
\text { appeared } \\
\text { Together in } \\
\text { the Dataset }\end{array}$ \\
\hline Fuck & shit & 0.631 & 63100 \\
\hline Fuck & people & 0.062 & 620 \\
\hline Fuck & hate & 0.041 & 410 \\
\hline fuck & love & 0.033 & 330 \\
\hline fuck & man & 0.03 & 300 \\
\hline fuck & god & 0.031 & 310 \\
\hline fuck & good & 0.027 & 270 \\
\hline fuck & talk & 0.023 & 230 \\
\hline fuck & feel & 0.022 & 220 \\
\hline
\end{tabular}

\begin{tabular}{|l|l|l|l|} 
fuck & life & 0.023 & 230 \\
\hline fuck & stupid & 0.023 & 230 \\
\hline fuck & bitch & 0.023 & 230 \\
\hline fuck & piece & 0.023 & 230 \\
\hline shit & holy & 0.1 & 100 \\
\hline shit & people & 0.058 & 580 \\
\hline shit & hate & 0.038 & 380 \\
\hline shit & love & 0.031 & 310 \\
\hline shit & man & 0.028 & 280 \\
\hline shit & god & 0.03 & 30 \\
\hline shit & good & 0.027 & 270 \\
\hline shit & talk & 0.023 & 230 \\
\hline shit & feel & 0.022 & 220 \\
\hline shit & life & 0.023 & 230 \\
\hline shit & stupid & 0.023 & 230 \\
\hline shit & piece & 0.025 & 250 \\
\hline
\end{tabular}

Table 2 presents findings of the most common profane bi-word patterns in cyberbullying incidents. The table information about total numbers of the words paired with another word. The supported values are an indication of how frequently the items (pair) appeared in the dataset. The words "fuck" and "shit" appeared 0.63 times and "shit" and "holy" appeared 0.10 times. The combine word "fuck" "shit" is a vulgar expression of terror, awe and shock frequently used when a person seen something for the first time. Combining two versatile words such as "fuck" and "shit" yields an extremely versatile combination. "Fucking shit" can be used to exclaim dismay or excitement, just about as versatile as either of its component words [25].

Table 3. Dominant Cyberbullying Words

\begin{tabular}{|l|l|l|l|}
\hline $\begin{array}{l}\text { Cyberbullying } \\
\text { Word 1 }\end{array}$ & $\begin{array}{l}\text { Cyberbullying } \\
\text { Word 2 }\end{array}$ & $\begin{array}{l}\text { Cyberbullying } \\
\text { Word 3 }\end{array}$ & Support \\
\hline fuck & shit & holy & 0.09 \\
\hline fuck & shit & people & 0.05 \\
\hline fuck & shit & hate & 0.035 \\
\hline fuck & shit & love & 0.028 \\
\hline fuck & shit & man & 0.025 \\
\hline fuck & shit & god & 0.027 \\
\hline fuck & shit & good & 0.024 \\
\hline
\end{tabular}




\begin{tabular}{|l|l|l|l|} 
fuck & shit & life & 0.021 \\
\hline fuck & shit & piece & 0.023 \\
\hline
\end{tabular}

Table 3 reveals the tri-words that were utilized to cyberbully be "fuck"+"shit"+"holy" support value of 0.090), followed by "fuck"+"shit"+"people" with a support value of 0.05 and "fuck"+"shit"+"hate" with a support value of 0.035 . This was the common vulgar expression / swearing word utilized by many Internet users. Table 3 result shows cyberbullying words that were utilized were considered common terms used however, if used in a sentence it may have different meaning and most can be correlated with rudeness and may inflict negative emotions and pain.

Table 4. Dominant Cyberbullying Three Word Patterns

\begin{tabular}{|l|l|r|c|r|}
\hline Premises & $\begin{array}{l}\text { Conclusi } \\
\text { on }\end{array}$ & Support & $\begin{array}{c}\text { Confiden } \\
\text { ce }\end{array}$ & \multicolumn{1}{|c|}{ Lift } \\
\hline $\begin{array}{l}\text { fuck, } \\
\text { piece }\end{array}$ & shit & $\begin{array}{r}0.02305 \\
1\end{array}$ & 0.99087 & $\begin{array}{r}1.36314 \\
9\end{array}$ \\
\hline $\begin{array}{l}\text { fuck, } \\
\text { shit }\end{array}$ & god & 0.0273 & 0.04325 & $\begin{array}{r}1.25669 \\
4\end{array}$ \\
\hline $\begin{array}{l}\text { fuck, } \\
\text { shit }\end{array}$ & people & $\begin{array}{r}0.04971 \\
3\end{array}$ & 0.07876 & $\begin{array}{r}1.02695 \\
2\end{array}$ \\
\hline $\begin{array}{l}\text { fuck, } \\
\text { holy }\end{array}$ & shit & $\begin{array}{r}0.08986 \\
6\end{array}$ & 0.97691 & $\begin{array}{r}1.34394 \\
1\end{array}$ \\
\hline $\begin{array}{l}\text { fuck, } \\
\text { life }\end{array}$ & shit & 0.02082 & 0.89498 & $\begin{array}{r}1.23123 \\
1\end{array}$ \\
\hline $\begin{array}{l}\text { shit, } \\
\text { good }\end{array}$ & fuck & $\begin{array}{r}0.02358 \\
2\end{array}$ & 0.87059 & $\begin{array}{r}1.11536 \\
7\end{array}$ \\
\hline $\begin{array}{l}\text { shit, } \\
\text { hate }\end{array}$ & fuck & $\begin{array}{r}0.03505 \\
4\end{array}$ & 0.92437 & 1.18427 \\
\hline $\begin{array}{l}\text { shit, } \\
\text { love }\end{array}$ & fuck & 0.02783 \\
1 & 0.90972 & $\begin{array}{r}1.16550 \\
4\end{array}$ \\
\hline $\begin{array}{l}\text { shit, } \\
\text { man }\end{array}$ & fuck & 0.024963 & 0.89354 & 1.144767 \\
\hline
\end{tabular}

\section{Conclusion}

Cyberbullying has become one of the major threats in our society today due to the massive damage that it can cause not only in the cyber world and the internet-based business but also in the lives of many people. The objective of this study is decode comments from the social networks and identify words to cyberbullying Lesbian, Gay, Bisexual, Transgender and Queer or Questioning (LGBTQ) victims and detect patterns and trends from the results to produce meaning and knowledge. This study utilized an unsupervised associative approach text analysis technique that extracts the relevant information from the unstructured text of 
cyberbullying messages. The prevalent words used to bully in the cyber is "fuck", "shit", Followed "holy", "people" and "hate". "Fuck" and "Shit" account almost half of all cyberbullying words and appear more that $75 \%$ in the dataset as the most frequently used words. The highest frequency of occurrence of words / word patterns were the combination of "fuck" + "holy" have the highest support and confidence, followed by "shit" + "holy". The terms "shit"+"hate"+ "fuck" with a positive lift value and "shit"+ "stupid" positive obtained the highest chance of togetherness / chance of utilizing both of these words to cyber bully. The combination of words / word patterns was considered abusive swearing is always considered rude when it is used to intimidate or humiliate someone. Understanding personal comments through the adoption of a new technology can be a better option. [26]. The results can be further explored and considered as a potential feature in a cyberbullying detection model using a machine learning approach. The output and results of this study will contribute to formulating future intervention to combat cyberbullying. Furthermore, the results can be utilized as a model in the development of a cyberbullying detection application based on the text relations / associations of words in the comments, replies, blog discussion and discussion groups across the social networks.

\section{References:}

[1] Blumenfeld, W. J., \& Cooper, R. M. (2010). LGBT and allied youth responses to cyberbullying: Policy implications. The International Journal of Critical Pedagogy, 3(1), 112.

[2] Hinduja, S., \& Patchin, J. W. (2011). Cyberbullying research summary: Bullying, cyberbullying, and sexual orientation. Cyberbullying Research Center: http://cyberbullying org/cyberbullying_sexual_ orientation_fact_sheet $p d \bar{f}$.

[3] Abreu, R. L. and Kenny, M. C. 2018. Cyberbullying and LGBTQ Youth: A Systematic Literature Review and Recommendations for Prevention. Retrieved from:

https://www.ncbi.nlm.nih.gov/pmc/articles/P MC7163911/pdf/40653_2017_Article_175.pd $\mathrm{f}$

[4] Patacsil, F. F. (2019). Analysis of cyberbullying incidence among Filipina victims: a pattern Recognition using association rule extraction. International Journal of Intelligent Systems and Applications, 11(11), 48.
[5] Hinduja, S. and Patchin, J. W. 2015. Bullying Beyond the Schoolyard: Preventing and Responding to Bullying, ( $2^{\text {nd }} E d$.) Corwin, A Sage Company. Retrieved from: https://books.google.com.ph/books?hl=en\&lr $=$ \&id=TQ2gBAAAQBAJ\&oi=fnd\&pg=PP1\& dq=Bullying+Beyond+the+Schoolyard:+Prev enting++and+Responding+to+Cyberbullying. \&ots $=2$ WXIHErW-

F\&sig=5Xp6Nhq4JmiPvJ0oS-5tnanD-

BA\&redir esc $=\mathrm{y} \# \mathrm{v}=$ onepage $\& \mathrm{q}=$ Bullying $\% 2$ 0Beyond\%20the\%20Schoolyard\%3A\%20Pre venting $\% 20 \% 20$ and $\% 20$ Responding $\% 20$ to $\%$ 20Cyberbullying.\&f=false

[6] Potha, N., \& Maragoudakis, M. (2014, December). Cyberbullying detection using time series modeling. In 2014 IEEE International Conference on Data Mining Workshop (pp. 373-382). IEEE.

[7] Sittichai, R. (2014). Information technology behavior cyberbullying in Thailand: incidence and predictors of victimization and cybervictimization. Asian Social Science, 10(11), 132.

[8] Garaigordobil, M. G., Larrain, E. L., Garaigordobil, M., \& Larrain, E. (2020). Bullying and cyberbullying in LGBT adolescents: Prevalence and effects on mental health. Comunicar. Media Education Research Journal, 28(1).

[9] Johnson, L. D., Haralson, A., Batts, S., Brown, E., Collins, C., Travis, A. V. B., and M. Spencer. 2016. Cyberbullying on Social Media Among College Students. Retrieved from:

https://www.counseling.org/docs/defaultsource/vistas/article_03b0bf24f16116603abca cff0000bee5e7.pdf?sfvrsn=2ea9442c _4

[10] Margono, B. A., Potapov, P. V., Turubanova, S., Stolle, F., \& Hansen, M. C. (2014). Primary forest cover loss in Indonesia over 2000-2012. Nature climate change, 4(8), 730-735.

[11] Powell, A., Scott, A., and N. Henry. 2020. Digital Harassment and abuse: Experiences of sexuality and gender minority adults. Retrieved from: https://journals.sagepub.com/doi/pdf/10.1177/ 1477370818788006

[13] Synyayeva, L., Verba, D., Yarchuk, A., Verkhovod, I. and Aleksandrov, D. (2021). Resources of Educational and Healthcare Industries and Population Welfare: Comparative Analysis in Post-socialist and OECD Countries, WSEAS Transactions on Business and Economics, vol. 18, pp. 531542. 
[13] Bouzahzah, M. (2021). Quality of the education system and economic growth. Projections in the case of Morocco, WSEAS Transactions on Business and Economics, vol. 18, pp. 949961.

[14] Walters, M. A., Paterson, J. and Brown, R. 2017. Hate Crimes Against Trans People: Assessing Emotions, Behaviors, and Attitudes Toward Criminal Justice Agencies. Journal of Interpersonal Violence, 35(21-22). Retrieved from:

https://doi.org/10.1177/0886260517715026

[15] Wiederhold, B. K. 2014. Cyberbullying and LGBTQ Youth: A Deadly Combination

[16] Collier, K. L., van Beusekom, G., Bos, H. M. W., and Sanfort, T. G. M. 2013. Sexual Orientation and Gender Identity/Expression Related Peer Victimization in Adolescence: A Systematic Review Associated Psychosocial and Health Outcomes. J Rex Ses, 50(3-4): 299 - 317. Retrieved from: doi: 10.1080/00224499.2012.750639

[17] Dragowski, E., Grossman, A. H., Halkitis, P. N. and DAugelli, A. R. 2011. Sexual Orientation Victimization and Posttraumatic Stress Symptoms among Lesbian, Gay, and Bisexual Youth. Journal of Gay \& Lesbian Social Services, 23(2):226-249. Retrieved from: https://www.researchgate.net/publication/254 363761 Sexual Orientation Victimization a nd_Posttraumatic_Stress_Symptoms_Among _Lesbian_Gay_and_Bisexual_Youth

[18] Brumer, A. P., Hatzenbuehler, M. L., Oldenburg, C. E., and Bocting, W. 2015. Individual - and Structural - Level Risk Factors for Suicide Attempts Among Transgender Adults. Behavioral Medecine, 41(3): 164-171. Retrieved from: https://doi.org/10.1080/08964289.2015.10283 $\underline{22}$

[19] Dinakar, K., Reichart, R., \& Lieberman, H. (2011, July). Modeling the detection of textual cyberbullying. In fifth international $A A A I$ conference on weblogs and social media.

[20] Bogartz, R.S. Interrater Agreement and Combining Ratings, University of Massachusetts, Amherst. http://people.umass.edu/ bogartz/Interrater\% 20Agreement.pdf

[21] Mavlutova, I., Lesinskis, K., Liogys, M., Hermanis, J. (2020). Innovative Teaching Techniques for Entrepreneurship Education in the Era of Digitalisation. WSEAS Transactions on Environment and Development, Volume 16, pp. 725-733.

[22] Chisag, J. C. C., Díaz, N. C. G., Calderón, F. M. M., Cruzado, J. G., Pisuña, F. E. Q.,
Carate, M. D. I., Baylón, A. R., and Ortiz, O. L. G. (2020). The Technology Acceptance Model in the Collaborative Learning of Web 2.0, Web 3.0 and Web 4.0: Higher Education Case Study. WSEAS Transactions on Environment and Development, Volume 16, 2020, pp. 680-688.

[23] Finn, E. (2017). Swearing: The Good, the Bad $\&$ the Ugly. ORTESOL Journal, 34, 17-26.

[24] Pinker, S. (2007). The Stuff of Thought: Language as a Window into Human Nature. New York, NY: Viking.

[25] Vingerhoets, A. J., Bylsma, L. M., \& De Vlam, C. (2013). Swearing: A biopsychosocial perspective. Psihologijske Teme, 22(2), 287304. Retrieved from http://www. academia.edu/9877052/Swearing_A_Biopsyc hosocial_Perspective.

[26] László Berényi, Nikolett Deutsch,

Assessment of the Future Role of Some Energy Sources by Higher Education Students in Hungary, pp.689-698, WSEAS Transactions on Environment and Development, Volume 16, 2020.

\section{Contribution of Individual Authors to the Creation of a Scientific Article (Ghostwriting Policy)}

Michael Acosta and Christine Lourrine Tablatin conceptualized and write the proposal and the introduction of the study. In addition, they help to gather the dataset.

Jennifer M Parrone gather and write related literature.

Frederick F. Patacsil process the dataset and write methodology and results $\&$ discussions

\section{Sources of Funding for Research Presented in a Scientific Article or Scientific Article Itself}

The authors would like to acknowledge the academic and financial support of Pangasinan State University (PSU).

\section{Creative Commons Attribution License 4.0 (Attribution 4.0 International, CC BY 4.0)}

This article is published under the terms of the Creative Commons Attribution License 4.0 https://creativecommons.org/licenses/by/4.0/deed.en US 